\title{
Dasar-Dasar Perancangan Alat Pemanggil Ikan
}

\author{
Sugiyanto*, Joga Dharma Setiawan, Faryan Nugraha, Rizkia Wira Yuwana \\ Departemen Teknik Teknik Mesin, Fakultas Teknik, Universitas Diponegoro \\ Jl. Prof. Sudharto, SH., Tembalang-Semarang 50275, Telp. +62247460059 \\ E-mail: edt.sugiyanto@gmail.com
}

\begin{abstract}
The fish caller is a device that uses the principle of underwater acoustics. Acoustic is a science that discusses sound waves and their propagation in a medium. So, this fish caller will produce a sound wave that will propagate in the water medium. The propagation of sound waves in water is influenced by many factors, including temperature, salinity, and depth. This study aims to obtain a basis for designing fish callers using the sound wave method. The main problem in the design of a fish caller is the occurrence of seawater absorption of acoustic waves thus shortening the range of calls. The method used in the research is to make a device that can produce a sound wave with a frequency that can be adjusted according to the frequency of the fish used as a summoning test, then testing the fish called in the laboratory. By observing changes in fish behavior, a conclusion can be made whether the fish is affected by the sound frequency or not. Based on the results of the design obtained this fish caller using LED lights and ICL8038 then amplified with OP-AMP 741 to issue the desired frequency. Furthermore, the tool was tested against red snapper, which has a sound frequency of $1000 \mathrm{~Hz}$, the results showed that red snapper responded to the call, this was indicated by a change in behavior of fish moving around the tool, as many as 70 times a lap within 1 hour of testing.
\end{abstract}

Key-words: The fish caller, prototype, underwater acoustics

\begin{abstract}
Abstrak
Alat pemanggil ikan merupakan suatu alat yang menggunakan prinsip akustik bawah air. Akustik merupakan ilmu yang membahas tentang gelombang suara dan perambatannya dalam suatu medium. Jadi, Alat pemanggil ikan ini akan menghasilkan suatu gelombang suara yang akan merambat pada medium air. Perambatan gelombang suara di dalam air dipengaruhi banyak faktor, diantaranya suhu, salinitas dan kedalaman. Penelitian ini bertujuan untuk mendapatkan suatu dasar perancangan alat pemanggil ikan menggunakan metode gelombang suara. Permasalahan utama pada perancangan alat pemanggil ikan adalah terjadinya penyerapan air laut terhadap gelombang akustik sehingga memperpendek jarak jangkau pemanggilan. Metode yang digunakan pada penelitian adalah dengan membuat alat yang dapat menghasilkan suatu gelombang suara dengan frekuensi yang dapat diatur sesuai dengan frekuensi ikan yang dipakai sebagai uji coba pemanggilan, selanjutnya dilakukan pengujian pemanggilan ikan di laboratorium. Dengan mengamati perubahan prilaku ikan dapat dibuat suatu kesimpulan apakah ikan tersebut terpengaruh oleh frekuensi suara apa tidak. Berdasarkan hasil perancangan diperoleh alat pemanggil ikan ini menggunakan lampu LED dan ICL8038 lalu diperkuat dengan OP-AMP 741untuk mengeluarkan frekuensi yang diinginkan. Selanjutnya alat tersebut diuji terhadap ikan kakap merah yang memiliki frekuensi suara $1000 \mathrm{~Hz}$, hasilnya menunjukkan bahwa ikan kakap merah merespon pemanggilan tersebut, hal ini ditunjukkan terjadinya perubahan perilaku ikan yang bergerak memutari alat tersebut, sebanyak 70 kali putaran dalam kurun waktu 1 jam pengujian.
\end{abstract}

Kata kunci: Alat pemanggil ikan, prototipe, akustik bawah air

\section{Pendahuluan}

Indonesia memiliki banyak wilayah laut, pesisir, dan pulau-pulau kecil yang luas dan bermakna strategis sebagai pilar pembangunan ekonomi nasional. Selain memiliki nilai ekonomis, sumber daya kelautan juga mempunyai nilai ekologis, di samping itu, kondisi geografis Indonesia terletak pada geopolitis yang strategis, yakni antara lautan Pasifik dan lautan Hindia yang merupakan kawasan paling dinamis dalam arus percaturan politik, pertahanan, dan kemanan dunia [1]. Potensi wilayah pesisir dan lautan Indonesia dipandang dari segi fisik, terdiri dari perairan nusantara seluas 2.8 juta $\mathrm{km} 2$, laut teritorial seluas 0.3 juta $\mathrm{km} 2$, perairan nasional seluas 3,1 juta km2, luas daratan sekitar 1,9 juta km2, dan Luas Wilayah Nasional 5,0 juta km2 [2]. Berdasarkan data Organisasi Pangan Dunia (FAO), produksi ikan meningkat dalam skala nasional pada tahun 2011 sebesar 955.520 ton. Kementerian Kelautan dan Perikanan (KKP) mencatat, potensi sumber daya ikan saat ini sudah mencapai 9,9 juta ton. Selain itu, potensi luas lahan budidaya juga mencapai 83,6 juta hektar [3]. 
Dengan besarnya potensi-potensi pada beberapa wilayah tersebut, diperlukan adanya inovasi pada sistem penangkapan ikan. Salah satu cara yang dikembangkan pada penelitian ini adalah alat pemanggil ikan, yang didasarkan pada sejumlah data-data bahwa ikan berkomunikasi dengan kelompoknya pada suatu frekuensi suara tertentu. Dengan demikian diperlukan suatu alat yang dapat mensimulasi suara ikan jenis tertentu, sehingga ikan-ikan tersebut akan bergerombol disekitar alat yang menimbulkan suara dengan frekuensi yang sama dengan kelompok ikan yang akan ditangkap. Pada akhirnya akan meningkatkan pendapatan nelayan dan juga memudahkan dalam menangkap ikan [4]. Akan tetapi nelayan yang menangkap ikan di Indonesia kurang memperhatikan dampak pengoperasian alat penangkap ikan yang minimal harus mampu menjawab tiga dampak utama, yaitu dampak terhadap lingkungan, dampak terhadap kelimpahan sumberdaya dan dampak terhadap target sumberdaya ikan [5]. Permasalahan yang dihadapi nelayan dalam kegiatan operasi penangkapan ikan adalah sulitnya menentukan daerah penangkapan yang tepat, karena nelayan masih menggunakan konvensional dengan mengandalkan panca indra seperti melihat tanda-tanda alam, cara coba-coba, naluri dan kebiasaan yang diwariskan turun-temurun. Cara yang lebih modern dalam menentukan daerah penangkapan ikan dengan menggunakan teknologi penginderaan jauh. Dengan teknologi ini dapat diketahui sebaran klorofil dipermukaan air laut yang merupakan parameter yang mengindikasikan bahwa perairan tersebut banyak terdapat ikan [6].

Lembaga Penelitian Oita Prefectural di Jepang pertama kali menerapkan metode pengkondisian suara dalam proyek peternakan mereka untuk mencegah ikan dari penyebaran dan untuk meningkatkan tingkat penangkapan ikan yang dilepas kembali.Penelitian yang telah dilakukan membuktikan bahwa ikan pada frekuensi bunyi tertentu akan merespon dan diikuti dengan perubahan tingkah laku, termasuk untuk menarik lawan jenisnya juga menggunakan suara [7]. Studi-studi ini menunjukkan bahwa, dengan sedikit pengecualian, ikan tidak bisa mendengar suara di atas sekitar 3$4 \mathrm{kHz}$, dan mayoritas spesies hanya mampu mendeteksi suara hingga $1 \mathrm{kHz}$ atau bahkan di bawah. Sebaliknya, seorang anak muda yang sehat dapat mendeteksi suara hingga sekitar $20 \mathrm{kHz}$, dan lumba-lumba dan kelelawar dapat mendeteksi suara hingga lebih dari $100 \mathrm{kHz}$. Ada juga studi tentang beberapa spesies ikan bertulang rawan, dengan hasil yang menunjukkan bahwa mereka mendeteksi suara tidak lebih dari 600 atau $800 \mathrm{~Hz}$ [8]. Adapun tujuan penelitian ini untuk membuat alat pemanggil ikan menggunakan variasi sinyal berbasis mikrokontroller. Sehingga dapat mempermudah nelayan dalam mendapatkan dan memanfaatkan potensi sumber daya laut yang sangat banyak di Indonesia.

\section{Material dan metode penelitian}

\subsection{Metode penelitian}

Penelitian dimulai dengan studi literatur sebagai langkah awal guna mendapatkan metode yang digunakan pada pembuatan alat pemanggil ikan yang berbasis mikrokontroller agar diperoleh alat yang mudah digunakan. Oleh karena itu, pengerjaan dibagi menjadi dua, yaitu secara mekanik dan elektrik, dimana pengerjaan secara mekanik meliputi perancangan desain case alat, permodelan dengan software Solidworks (gambar 1), dilanjutkan dengan membuat alat mekanik.

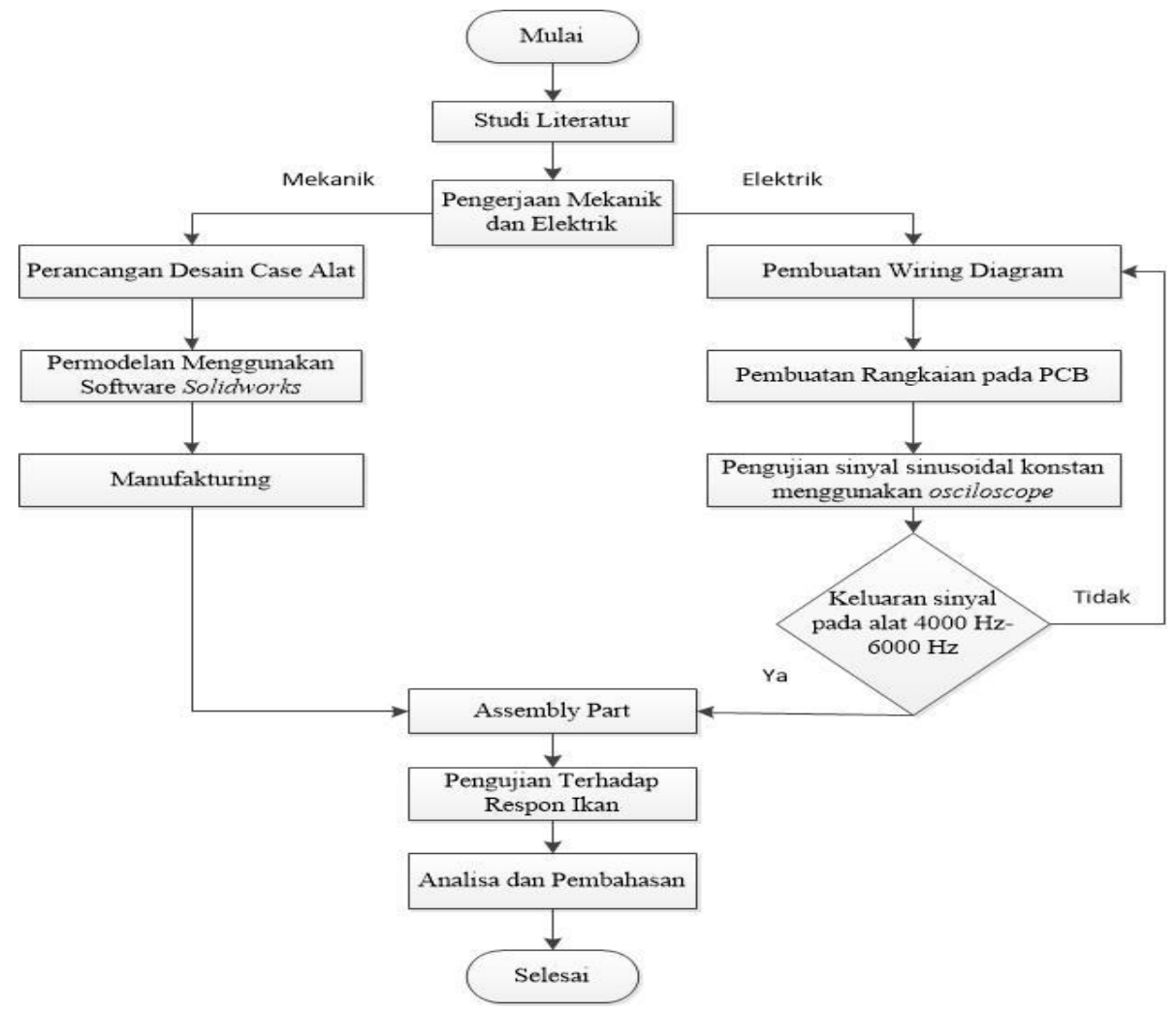

Gambar 1. Diagram alir kegiatan penelitian 
Selanjutnya bagian elektrik terlebih dahulu dibuat wiring diagram (gambar 3) sehingga dalam pembuatan diatas pcb tidak terdapat kesalahan yang mengakibatkan alat mengalami kenaikan tegangan listrik. Setelah dipasang pada PCB, alat diuji keluaran sinyalnya melalui oscilloscope dan diatur secara konstan. Setelah mekanik dan elektrik dilakukan, kedua part digabung menjadi sebuah alat pemanggil ikan (gambar 2) yang akan diuji dan di analisa keluaran dalam air dan respon terhadap ikan ketika alat dimasukkan kedalam kolam uji.

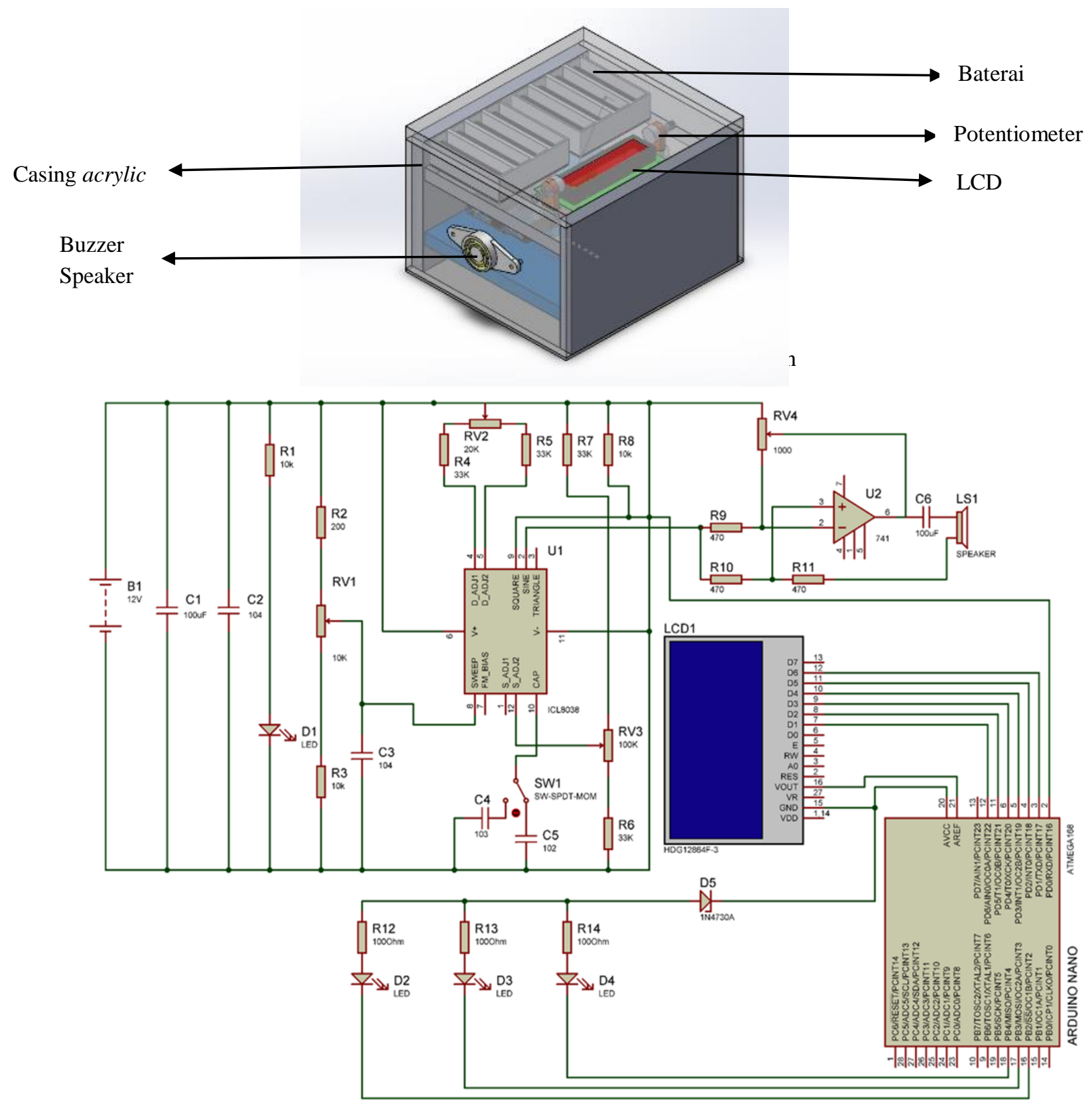

Gambar 3. Rangkaian Elektronik Gelombang Sinusoidal

\section{Hasil dan pembahasan}

\subsection{Hasil Pengujian Ukur Frekuensi Prototipe}

Pengujian dilaksanakan di dalam kolam buatan yang terletak dilaboratorium Robotics dan Automation lantai 5 gedung Unit Pelaksanaan Terpadu Universitas Diponegoro Tembalang Semarang. Dalam pengujian ini setelah dilakukan pengujian dengan cara merekam intensitas dan frekuensi suara dalam air kemudia mengolah datanya melalui persamaan fourier menggunakan software matlab. Untuk pengujian pertama dalam air pada saat sebelum ikan dimasukkan untuk mendapatkan frekuensi dan hearloss dalam air saat alat diletakkan dengan jarak $50 \mathrm{~cm}$ dari sumber suara. Dilakukan pengcodingan sebagai berikut:

- Memasukkan data sumber rekaman kedalam software. 
$\% \%$ Load data

close all; clc;

uiopen('Suara_009.m4a'); \% load Data

Sample $=($ 'Suara_009.m4a');

- Membuat plotting antara data sumber suara berdasarkan satuan jumlah sample suara selama direkam.

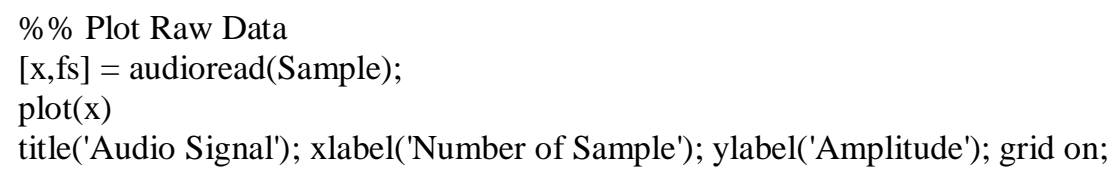

- Memisahkan jumlah data sampel yang akan dianalisa sehingga mengurangi noise signal yang terjadi akibat gesekan udara atau kebisingan yang diluar suara objek.Perbandingan grafik antara waktu dan Amplitude.

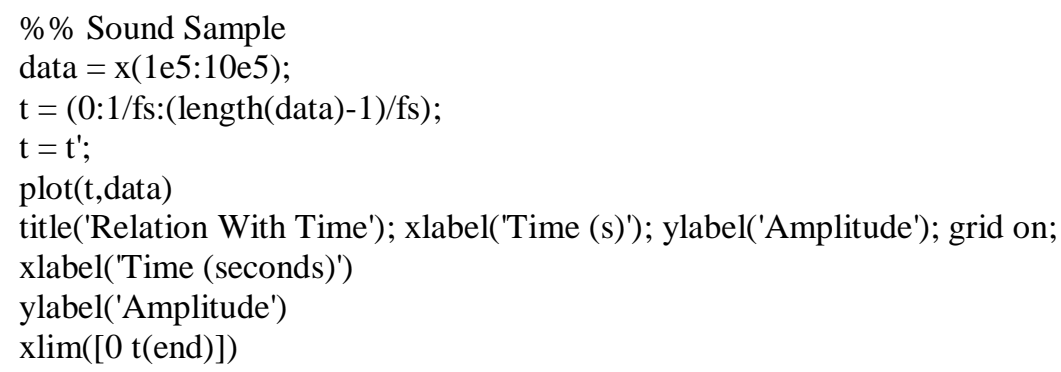

- Membuat persamaan fft terhadap data yang telah dipisah berdasarkan satuan waktu dan jumlah sampel, menggunakan fungsi DFT signal

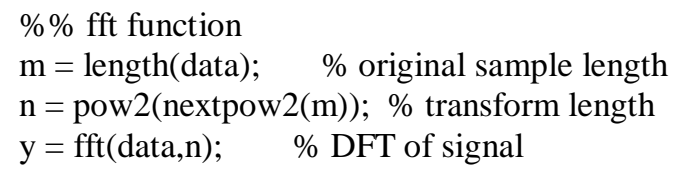

- Plotting hasil perhitungan fourier agar bisa dilihat seberapa besar hearloss yang terjadi dalam air.

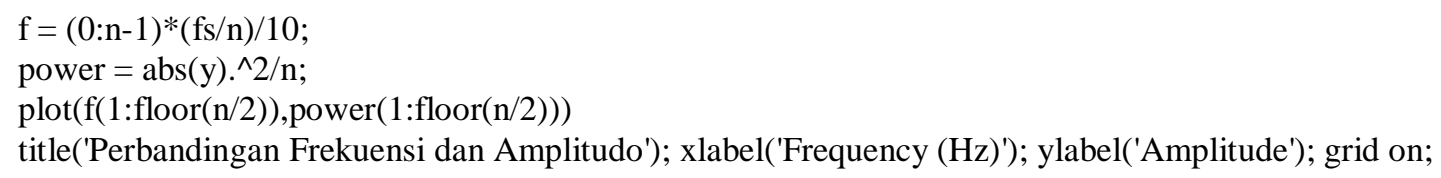

Berdasarkan hasil yang diperoleh dari percobaan dan olahan data melalui matlab maka dapat dilihat bahwa masingmasing pengujian menghasilkan frekuensi dan amplitude suara yang berbeda, dimana sinyal yang diberikan untuk ikan ditunjukkan pada Tabel 1 .

Tabel 1 Amplitudo dan frekuensi pengujian

\begin{tabular}{cccc}
\hline Data & Sinyal & Amplitude max(dB/Hz) & Pada Frekuensi \\
\hline $\mathbf{1}$ & Suara_27Agt008 & 0.4 & 142 \\
$\mathbf{2}$ & Suara_27Agt009 & 2.9 & 650 \\
\hline
\end{tabular}

\subsection{Hasil Pengujian Prototipe terhadap Objek}

Pengujian dilaksanakan atas seizin pihak Laboratorium Robotics dan Automation UPT. Pengujian dilaksanakan di dalam kolam buatan yang terletak dilaboratorium Robotics dan Automation lantai 5 gedung Unit Pelaksanaan Terpadu Universitas Diponegoro Tembalang Semarang. Dalam melakukan pengujian respon ikan terhadap alat, penguji menggunakan 4 ekor ikan kakap merah dimana objek penelitian dimasukkan kedalam kolam sehari sebelum dialkukan pengujian agar ikan terbiasa terhadap lingkungan yang baru. Kemudian peneliti menggunakan 3 waktu pengujian yaitu pagi siang dan malam, sebelum dimasukkan alatnya ikan di beri makan sehari sebelumnya dengan jadwal yang sama 
saat alat dimasukkan keesokan harinya, sesuai dengan yang terlihat pada table dan grafik dibawah, ikan cenderung lebih banyak melakukan aktifitasnya pada siang hari, dimana pada malam hari ikan lebih tertarik dengan cahaya lampu daripada suara yang dihasilkan. Peneliti melakukan pengujian dengan memperhatikan factor-faktor yang dapat mempengaruhi percobaan, seperti suhu, kedalaman air, salinitas air.

Percobaan ini dilakukan dengan mengamati perilaku ikan selama kurun waktu tertentu dimana khususnya melihat apakah ikan akan mendekati alat pemanggil atau justru menjauhi alat. Apabila ikan bergerak mengitari alat pemanggil maka dianggap ikan tertarik untuk mendatangi alat tersebutdan jika perilaku ikan tidak seperti itu, maka ikan tidak tertarik atau merasa tidak terpanggil oleh alat itu. Untuk itu pengukuran dilakukan untuk melihat berapa jumlah ikan mengitari alat tersebut dalam kurun waktu tertentu. Setelah melakukan percobaan ini dapat dilihat hasilnya melalui Table 2 dan grafik Gambar 6 berikut.

Tabel 2. Jumlah Respon Ikan Selama Kurun Waktu Tertentu

\begin{tabular}{cccc}
\hline \multirow{2}{*}{ Waktu (menit) } & \multicolumn{3}{c}{ Jumlah Putaran ikan (Respon Ikan) } \\
\cline { 2 - 4 } & Pagi & Siang & Malam \\
20 & 53 & 65 & 41 \\
30 & 37 & 78 & 33 \\
40 & 48 & 67 & 28 \\
50 & 53 & 73 & 26 \\
\hline Rata-rata & 43 & 70 & 28 \\
\hline
\end{tabular}

\subsection{Dasar-dasar perancangan}

Berdasarkan hasil uji coba prototipe alat pemanggil ikan ini, dapat dijelaskan bahwa prototipe ini digunakan sebagai dasar-dasar perancangan untuk mengembangkan prototipe dengan jarak jangkauan pemanggilan digunakan sebagai dasar parameter dasar kemampuan alat pemanggil ikan. Perlu dipahami bahwa pada alat pemanggil ikan ini ada dua fungsi yang dapat dipisahkan, yaitu fungsi alat penghasil gelombang sinusoidal dan fungsi alat untu memperkuat gelombang tersebut untuk mencapai jarak tertentu. Dengan membagi fungsi tersebut, dapat digunakan bahwa wirring diagram yang telah ditunjukkan merupakan dasar penyusunan alat penghasil gelombang sinusoidal. Selanjutnya untuk lebih memperpanjang jarak jangkauan dapat digunakan alat yang berfungsi untuk memperkuat kemampuan rambat gelombang sinusoidal di dalam air.

\section{Kesimpulan}

Pengujian menggunakan alat pemanggil ikan dengan sinyal gelombang sinusoidal menunjukkan jumlah rata-rata ikan mengelilingi alat sebanyak 46 kali pada pagi hari, 70 kali pada siang hari dan 31 kali pada malam hari dalam rentang waktu 1 jam setelah alat dinyalakan. Berdasarkan variasi sinyal yang dilakukan ikan cenderung lebih banyak menghampiri alat pada saat siang dimana amplitude yang dihasilkan pada dua kali percobaan sebesar $0.4 \mathrm{~dB} / \mathrm{Hz}$ dan 2.9 dB/Hz pada frekuensi $142 \mathrm{~Hz}$ dan $650 \mathrm{~Hz}$. Alat pemanggil ikan setelah diukur diudara dan dimasukkan kedalam air untuk dianalisa menggunakan matlab memiliki hearloss terbesar pada kedalaman $0.5 \mathrm{~m}$ diudara sebesar $3.7 \mathrm{~dB} / \mathrm{m}$ dan hearloss terbesar pada kedalaman $2 \mathrm{~m}$ diair sebesar $9.286 \mathrm{~dB} / \mathrm{m}$. Prototipe ini dapat digunakan sebagai dasar perancangan alat pemanggil ikan dengan memisahkan alat penghasil frekuensi sinusoidal dan alat penguatan sinyal

\section{Daftar Pustaka}

[1] Statistik Perikanan, 2013 Kekayaan Ikan Tangkap Laut Indonesia. Kementrian Perikanan dan Kelautan, Indonesia.

[2] Manik, Henry, 2015, Teknologi Akustik Bawah Air: Solusi Data Perikanan Laut Indonesia. Tugas Akhir. Institut Pertanian Bogor, Indonesia.

[3] Winn, H.E. 1972, Acoustic discrimination by the toadfish with comment on signal system. Plenum Press, New York.

[4] Popper, Arthur N. 2008, Effects of Mid- and High-Frequency Sonars on Fish. LLC Rockville, United States.

[5] Kim, Jaims N., Steward, Melvin E. 1998, Sound and Light Emitting Fish Lure and Method of Attracting Fish. US Patent, 6,098,331.

[6] Hawkins, A.D., 1983, Hearing and Sound Communication underwater. Academic Press, New York.

[7] Multon, J.M. 1963, Acoustic behavior of fishes. Elsevier, Amsterdam.

[8] Kuperman, William A., Roux, Philippe. 2009, Underwater Acoustic. Springer. University of California, San Diego.

[9] Kraus, Dieter. 2010, Fundamentals of Ocean Acoustic. Springer. Hochshule University of Bremen, Jerman.

[10] Chaniotakis. Cory. 2006, Non Inverting Amplifier. Module. Texas Instrument, Amerika Serikat. 